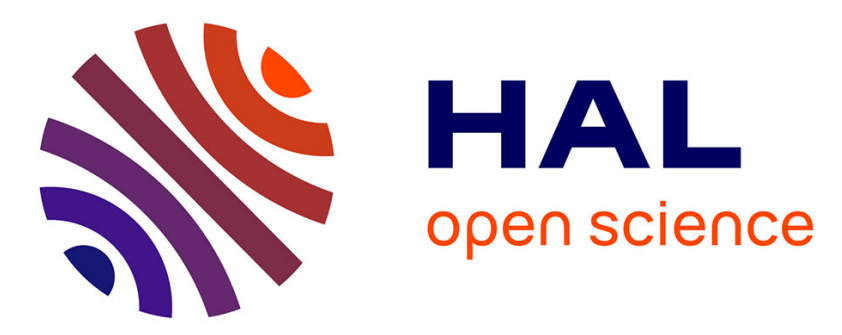

\title{
Ability of quality controllers to detect standard scratches on polished surfaces
}

Théodore Puntous, Sophie Pavan, David Delafosse, Michel Jourlin, Joël Rech

\section{To cite this version:}

Théodore Puntous, Sophie Pavan, David Delafosse, Michel Jourlin, Joël Rech. Ability of quality controllers to detect standard scratches on polished surfaces. Precision Engineering, 2013, 37 (4), pp.924-928. 10.1016/j.precisioneng.2013.03.001 . emse-00959569

\section{HAL Id: emse-00959569 \\ https://hal-emse.ccsd.cnrs.fr/emse-00959569}

Submitted on 24 Aug 2021

HAL is a multi-disciplinary open access archive for the deposit and dissemination of scientific research documents, whether they are published or not. The documents may come from teaching and research institutions in France or abroad, or from public or private research centers.
L'archive ouverte pluridisciplinaire HAL, est destinée au dépôt et à la diffusion de documents scientifiques de niveau recherche, publiés ou non, émanant des établissements d'enseignement et de recherche français ou étrangers, des laboratoires publics ou privés. 


\title{
Ability of quality controllers to detect standard scratches on polished surfaces
}

\author{
T. Puntous ${ }^{\mathrm{a}, c, \mathrm{~d}, *}$, S. Pavan ${ }^{\mathrm{b}}$, D. Delafosse ${ }^{\mathrm{c}}$, M. Jourlin $^{\mathrm{d}}$, J. Rech ${ }^{\mathrm{a}}$ \\ a Université de Lyon, Ecole Nationale d'Ingénieurs de Saint-Etienne, Laboratoire de Tribologie et Dynamique des Systèmes, CNRS UMR 5513, 58 Rue Jean Parot, \\ 42000 Saint-Etienne, France \\ ' Université de Lyon, Ecole Centrale de Lyon, Laboratoire de Tribologie et Dynamique des Systèmes, 36 Avenue Guy de Collongue, 69134 Ecully Cedex, France \\ ${ }^{\mathrm{c}}$ Ecole Nationale Supérieure des Mines, SMS-EMSE, CNRS:UMR5307, Laboratoire Georges Friedel, 158 Cours Fauriel, F-42023 Saint-Etienne, France \\ d Université de Lyon, Université Jean Monnet, Laboratoire Hubert Curien, UMR CNRS 5516, 18 Rue du Professeur Benoît Lauras, 42000 Saint-Etienne, France
}

The production of polished metal surfaces addresses a large number of fields such as medical prostheses, jewellery or moulds. These surfaces are checked by people who rarely agree on the definition of the right geometry limit of scratches. The aim of this work is to study human vision of scratches. The first step was to produce calibrated scratches barely visible by the human eye on polished metal surfaces in order to define standard samples for polishing quality control. A nanoindenter with a Berkovich tip was used to produce these scratches. These standard samples were shown to polishing controllers. They were asked to perform a research task leading to the establishment of two thresholds that characterize the visualization of scratches: a visibility threshold as well as an acceptability threshold.

\section{Introduction}

The polishing process of metal surfaces is the final finishing step of many industrial applications. Objects with a mirror polished surface can be found in all fields whether in medicine (prostheses, surgery tools), in jewellery (watch, ring) or in moulds and matrix production. Mirror polishing is not always intended to establish a functional surface. It usually gives the impression of quality and luxury. Polishing quality control is exclusively performed by individuals considered to be trained subjects or, in the company as experts due to their extensive experience in the trade. They try to detect scratches generated by the previous manufacturing operations that polishing might not have removed. Nevertheless, it is difficult for them to express a criterion and quantitative value.

Perception is not only the acquisition of information by sensors. Sensation is the result of the stimulation of a sense organ, a psychological treatment leading to a conscious or unconscious response. Instead, perception is the translation of multiple sensory information. For a standard controller, his final decision is thus a combination of his individual expectations, experience, and sensory treatments. The visual search tasks performed daily lead to

\footnotetext{
* Corresponding author at: Université de Lyon, Ecole Nationale d'Ingénieurs de Saint-Etienne, Laboratoire de Tribologie et Dynamique des Systèmes, CNRS UMR 5513, 58 Rue Jean Parot, 42000 Saint-Etienne, France. Tel.: +33 0477437567.

E-mail address: theodore.puntous@enise.fr (T. Puntous).
}

a noticeable improvement in performance and automation thereof [9]. Experts are trained first by their company. Their judgment then adapts gradually to the way they operate and their perception. The research task of polishing defects, being altered by experience, is then individual. When looking at a surface, experts have different visual skills that lead to different decisions. Some of them will see a scratch and others will not. This is called the detection or absolute threshold. The smallest stimulus that induces a just noticeable sensation has been one significant research field. The visual perception measurement cannot be limited to a visual acuity establishment. Psychophysics precisely aims to quantify the relation between physical stimuli, sensations and perception through experimental tests $[2,9]$. The same individual sensation may not lead to the same judgment of a defect. Some of experts will believe that a defect is acceptable, while others will consider it to be unacceptable. This acceptability threshold also depends on companies and products. For instance, an expert will be more demanding for a scratch on a surface that is highly visible by the customer rather than one on a hidden surface. Below the detection limit, no one will see the scratch. Above a certain scratch size, all individuals will see the scratch and agree to reject it. Between the two extremes, the visibility and acceptability threshold vary according to the experts. This causes problems with customers or over-quality problems and higher costs for manufacturers. Sensory analysis is based on the foundations of psychophysics. It is intended to measure similar reactions and feelings according to a panel of individuals. These include applications to standardize quality control of a product, 


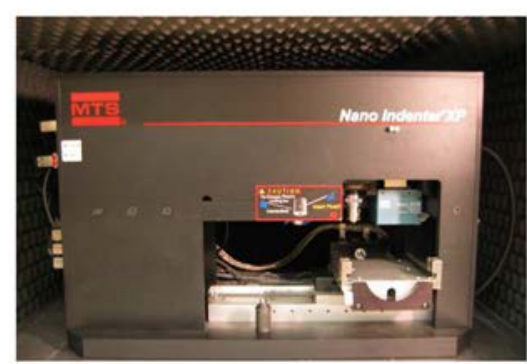

(a)

(b)

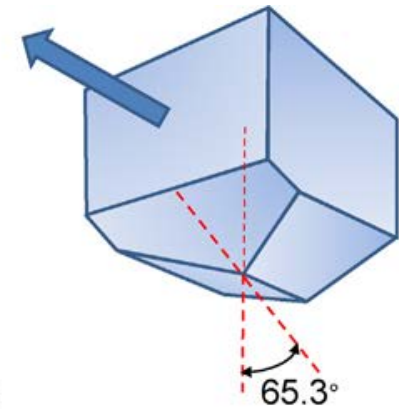

(c)

(d)
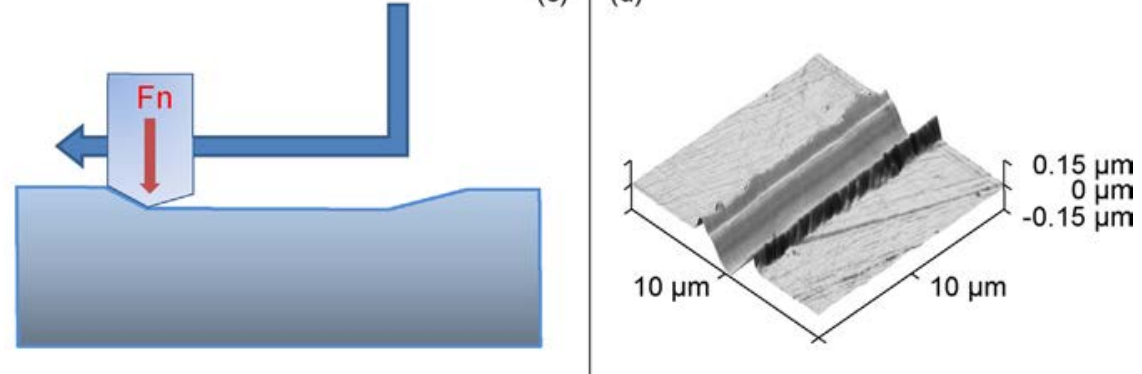

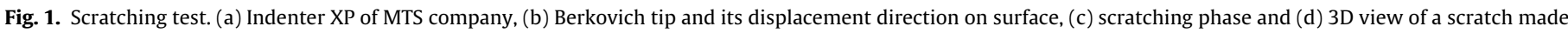
with a normal force of $6600 \mu \mathrm{N}$ characterized by means of an AFM (atomic force microscope).

study human perception with a process change, or the evolution of a panel $[1,3,4,8]$. The development of a sensory analysis from standard samples and similarity trials is established in this paper. The panel used and the procedure of the analysis is detailed afterwards.

A method for standard scratch generation is as well suggested in order to calibrate the experts for the inspection of flat polished metal surfaces. Scratches are the most common defects encountered in a company [3]. The standard samples range from the invisible to the visible in order to study human perception as a whole. Polishing experts perform their control from a conventional distance of approximately $30 \mathrm{~cm}$ in a jewellery quality control company. From this distance, the human eye has a resolution of about $700 \mathrm{~nm}\left(0.5^{\prime \prime}\right.$ as the minimum visible described by Hecht and Mintz [5]). Standard scratches are supposed to be from a few hundred nanometers to several micrometers wide to make sure that they cover the spectrum from the invisible to the very visible. Nanoindentation systems were originally designed to determine the mechanical properties of materials [6]. The indentation is made perpendicular to a flat surface. For this study a horizontal displacement is also used for scratching tests.

The following sections reveal the creations of the standard samples. A sensory analysis is then exposed in order to estimate the visibility and acceptability thresholds.

\section{Method for the creation and characterization of standard scratches}

\subsection{Creation of the samples set}

To create reproducible and reliable standards, a precise method for creating surfaces was established. Various polishing stages are rigorously followed to ensure the process repeatability.

The samples are cylindrical pellets $(\varnothing=15 \mathrm{~mm}, h=5 \mathrm{~mm})$ of $316 \mathrm{~L}$ stainless steel. They were polished mechanically using a set of SiC abrasive papers. The final polishing step was carried out on polishing lathes coated with a polishing paste to achieve a Ra roughness of $0.01 \mu \mathrm{m}$. The standard scratches are supposed to range from the invisible to the visible. In order to achieve this, the XP nanoindenter from MTS (Fig. 1) was used with a Berkovich tip. The Berkovich tip is a triangular diamond pyramid. Its faces are inclined relatively to the vertical axis with an angle of $63.5^{\circ}$ and move side-in-front as described in Fig. 1b.

\subsubsection{Constant parameters}

- Feed rate of the indenter on the surface: $10 \mu \mathrm{m} / \mathrm{s}$.

- Scratch length: $2.8 \mathrm{~mm}$.

- Indenter type: Berkovich side-in-front.

\subsubsection{Variable parameter}

- Normal force Fn prescribed: 530, 800, 1200, 1850, 2800, 4300, 6600 and $10,000 \mu \mathrm{N}$.

\subsection{Scratching procedure}

The indenter moves vertically to come into contact with the sample with a low load. It then moves horizontally along a distance of $2.8 \mathrm{~mm}$ by automatically controlling the normal force $F n$. The small sizes of the scratches cannot be acquired by means of a conventional sclerometer. Before each test, the Berkovich tip was controlled by a scanning electron microscope to ensure that it was not damaged. Each of the eight experimental conditions was conducted two times to estimate the stability of the results. All scratches thus formed were measured with a Nanoman atomic force microscope from Veeco Company in contact mode (Figs. $1 \mathrm{~d}$ and 2 ). Three images of the surface were calculated in three positions (beginning, middle and end) for each scratch in order not to focus on only one specific area of scratches. Two profiles were extracted for each image as displayed in Fig. 2a, namely 6 profiles. The two perpendicular profiles per images were made in order to remove random noise of the sample surface that could alter final results. Three length parameters were recorded with the same procedure: width between two peaks $a$, width at the surface $b$ and depth $c$ as shown in Fig. 2b. Parameter $a$ expresses the width of a scratch at maximum residual pile-up height. Parameter $b$ is the width for a depth below surface that equals zero (average plane level). Parameter $c$ exposes the residual 
(a)
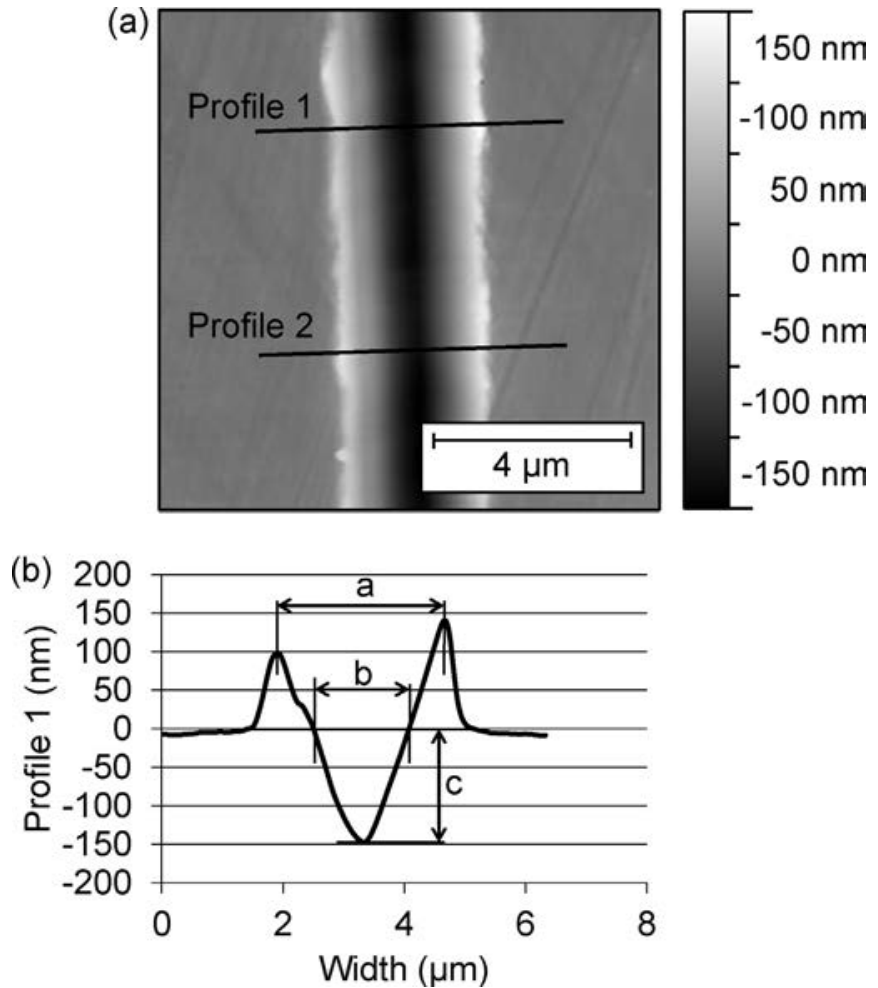

Fig. 2. Measurement of the shape of stripes. (a) AFM image of a scratch made with a normal force of 6600 and (b) profile characterization: a. Width between two peaks; b. Width at the surface and c. Depth.

depth after scratching. Parameters $a$ and $b$ have being measured parallel to the average plane of the surface. Parameter $c$ has been measured perpendicular to the average plane.

\subsection{Results}

Fig. 3 plots the evolution of the three characteristic parameters ( $a$ : width between two peaks, $b$ : width at the surface, $c$ : depth) of the scratches created. Standard deviation is drawn with error bars in order to expose the variation of the recorded results. Each point represents the average of 12 points. Indeed, 2 scratches were made for each configuration, 3 scratch images were measured by means of the atomic force microscope and 2 profiles were extracted from each image. It appears that parameter $b$ expressing the width of the scratches (Fig. $2 \mathrm{~b}$ ) begins at $400 \mathrm{~nm}$ for the lowest load $(F n=530 \mu \mathrm{N})$. This parameter $b$ rises to about $2000 \mathrm{~nm}$ (and parameter $a$ to $3200 \mathrm{~nm})$ for the highest load $(F n=10,000 \mu \mathrm{N})$. There is a correspondence of the parameters with the theoretical visibility threshold [5] set at $700 \mathrm{~nm}$. Given the objective of making scratches less than $700 \mathrm{~nm}$ and scratches above $1000 \mathrm{~nm}$, the system developed seems to meet the specifications. In order to properly evaluate the real visibility of these scratches a sensory analysis has been conducted in a polishing quality control company.

\section{Sensory analysis}

\subsection{Experimentation basis}

This paper exposes the evaluation of the performance of quality controllers in a daily classical controlling task. Twelve subjects from a jewellery quality control company participated in the study. Their role in the company stood at different levels of control of production, but all were used to control daily polished products. The surfaces were considered to be perfectly polished before the

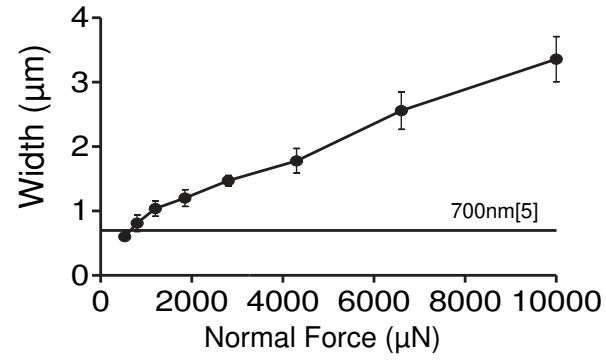

(a)

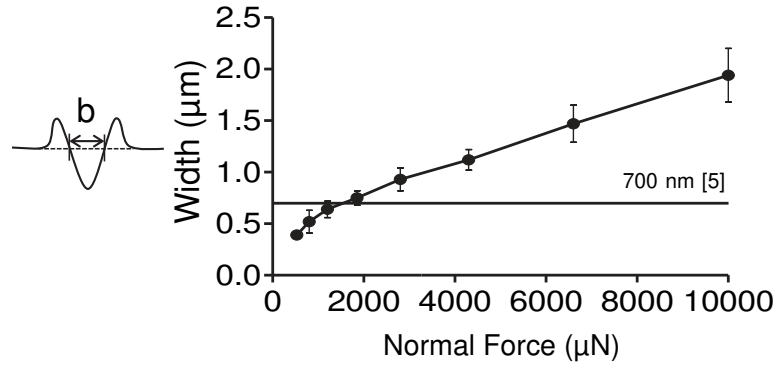

(b)

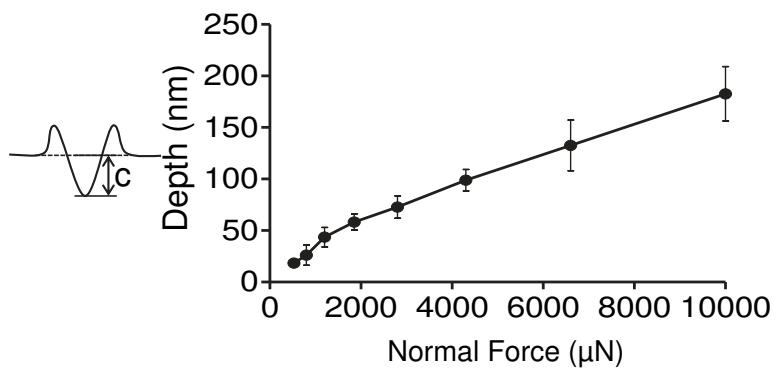

(c)

Fig. 3. Influence of the normal force on the scratch parameters. (a) Width between two peaks, (b) width at the surface and (c) depth.

scratching step by the panel. There still remained scratches but none of them were confirmed visible by this panel. 17 samples were used for the study. One of them had no visible scratches and was selected as a standard comparison sample. The 16 others were the previously exposed samples. One scratch per sample has been made and range from the hypothetical invisible (width $400 \mathrm{~nm}$ ) to the very visible (width $2000 \mathrm{~nm}$ ) depending on the parameter $b$.

\subsection{Procedure}

The scratches were positioned at different locations on each sample so as to limit the phenomenon of adaptation [7]. The illuminating light was a fluorescent lamp with a light output controlled at 2000 lux. The subjects participated in a research task. The subjects were placed in normal quality control conditions. The viewing distance was set at $30 \mathrm{~cm}$ in accordance with the conventions of control given by the company. The subjects seated were free in the sample handling in so far as they respected the distance control. Each subject was then informed of the procedure without knowing the ultimate goal. The control sample was first shown in order to fix a reference for the remainder of the task. The standard samples were subsequently presented one by one in random order as in a constant stimuli situation [2].

The subjects did not know the severity of the scratch which was on the sample. They were asked to write down if a scratch was visible on the polished surface. No time limit was imposed. They were suggested to keep throughout the procedure a similar attitude to 
standard quality control. To ensure the proposal, the exact number of tests was not spelled out to avoid disruptions.

The subjects were informed that there were no correct answer but only personal impression in order to limit too conservative researches. The experiment was defined once and for all as the evaluation of a defect in the worst case. The standard defect was thus representing a scratch on a surface clearly visible by any client. For each sample, the subjects noted the position of a visible scratch in order to properly write their own vision on a sheet of paper. Since each scratch has been randomly presented, this information is needed in order to confirm whether the subject has detected a real standard defect or not. They were also asked to note if they would consider a visible scratch acceptable or not in a classical jewellery quality control.

\subsection{Results}

The absolute threshold is described as the lowest value perceived by a subject. In this study, the absolute threshold determines the point at which the experts perceive a scratch on the polished surface. Sensory analysis data are collected to form profiles of perception.

The data gathered are binary (seen/not seen, acceptable/ unacceptable). Each result reported is an inseparable combination of several physical and cognitive factors. It is impossible to determine which the subject is the most able to detect scratches. This test tends to favor positive responses for unwise subjects and negative responses for those most cautious.

Although the subjects were warned that there was no correct answer, a remaining pressure to respond incorrectly cannot be avoided during the experiment. The subjects reported to feel the need to concentrate hard for this task. Subjects with a low threshold response to the stimuli are not necessary the best at detecting scratches. The position in the company, the experience, expectations and behavior of each subject creates variations in the results. For instance, it is likely that a subject in charge of a quality center accepts more defects than conventional controllers because of well-known over-quality issues. More further training with standards may increase similar responses for one stimuli. Debrosse et al. [1] explain that "standardization helps the controller to be exhaustive during the detection task and opens access to information for the evaluation task. It also reduces practice variability during the detection process".

In order not to assume that a subject is actually better than another, an average profile of the panel has been drawn in Figs. 4 and 5. Each point represents the mean of two experimentations (two for the visibility tests and two for the acceptability test). Each session also includes data from the 12 subjects. Standard deviation is plot on original data for information with error bars in order to represent the dispersion of the subjects from a standard one. Scratches obtained with the same configuration are also congregated. Therefore each point has been obtained using 48 raw data. The 8 samples are ordered in increasing order of size. As predicted, the subjective nature of this research task is visible from the wide dispersion of data. The scratches dimensions are appropriate in the study of the absolute threshold as sensory responses clearly range from visible to invisible.

The stimuli perceived by the subjects is a combination of the scratch shape and the reflecting light. The shape of scratches (the width between two peaks, the width at the surface and the depth) is set on the abscissa in order to define the intensity of defects.

The absolute threshold of visibility is a perceived stimulus in $50 \%$ of cases [2]. The method of constant stimuli allows to remove the component of adaptation because the subject cannot consciously or unconsciously guess the intensity of each exposed stimulus. This threshold is the point where a real change in perception is observed.

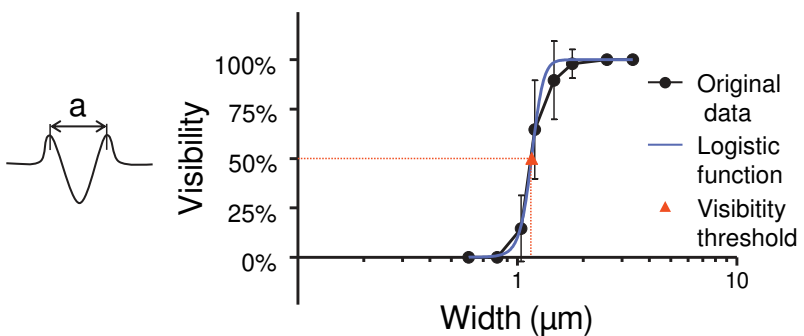

(a)

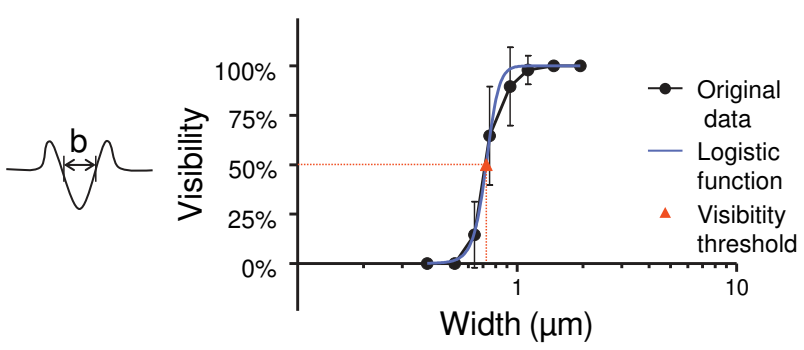

(b)

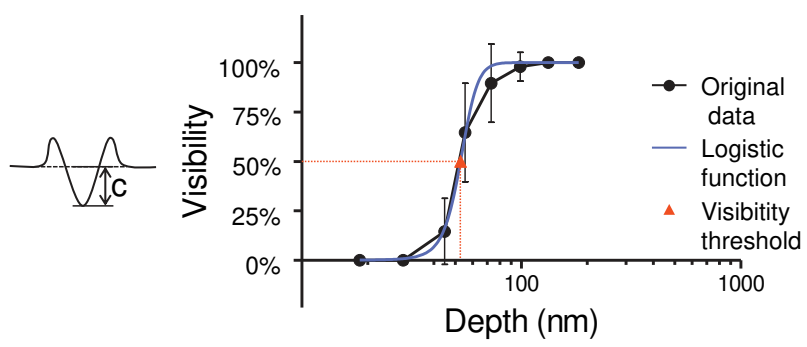

(c)

Fig. 4. Visibility of the scratches as a function of the parameters of the scratch. (a) Width between two peaks, (b) width at the surface and (c) depth.

Theoretically, if the subjects had a good sensitivity to a stimulus, their response would increase from 0 to $100 \%$ of detection with an infinite slope. The physical value of detection, given for $50 \%$ of detection gives the clear limit where the experts may have a random decision. A non-linear regression is calculated on the point cloud data with a logistic function (Eq. (1)) in order to estimate this threshold.

$v(p)=\frac{1}{1+\alpha e^{-\beta p}}$

With $v(p)$ the visibility of a scratch as a percentage and the parameter of scratch size $p . \alpha$ and $\beta$ are the two parameters of the logistic function. The regression has been performed with the parameters mentioned above and the visibility results. The same procedure has been followed for the acceptability results. These threshold are plotted on Figs. 4 and 5.

The visibility and acceptability thresholds are listed in the Table 1 . The absolute threshold determined by Hecht and Mintz is $0.5^{\prime \prime}$ [5]. From the conventional distance of $30 \mathrm{~cm}$, the angle is corresponding to a $0.74 \mu \mathrm{m}$ width. This number is variable between individuals but is consistent with the results found with sensory analysis. Indeed, the visibility of the scratch expressed with

Table 1

Results of the sensory analysis.

\begin{tabular}{lll}
\hline Shape parameter & Visibility threshold & Acceptability threshold \\
\hline$a$ : width between two peaks & $1.16 \mu \mathrm{m}$ & $1.40 \mu \mathrm{m}$ \\
$b$ : width at the surface & $0.72 \mu \mathrm{m}$ & $0.88 \mu \mathrm{m}$ \\
$c$ : depth & $53 \mathrm{~nm}$ & $69 \mathrm{~nm}$ \\
\hline
\end{tabular}




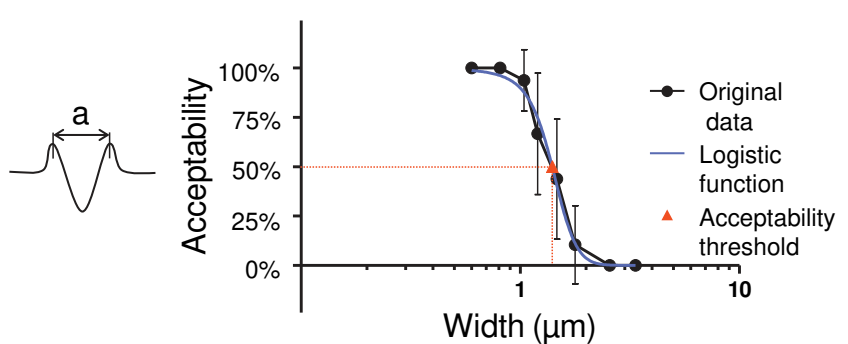

(a)

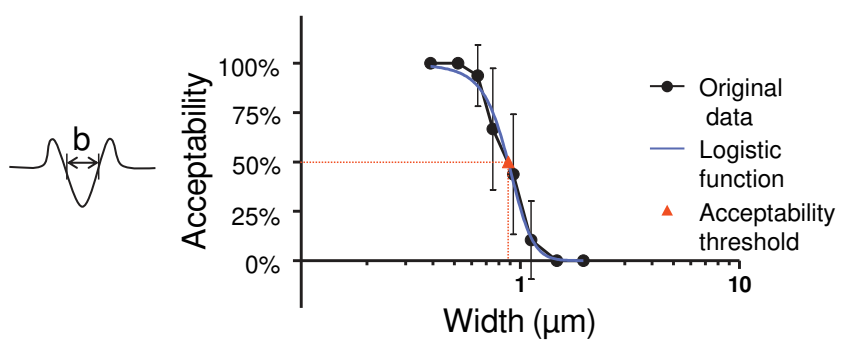

(b)

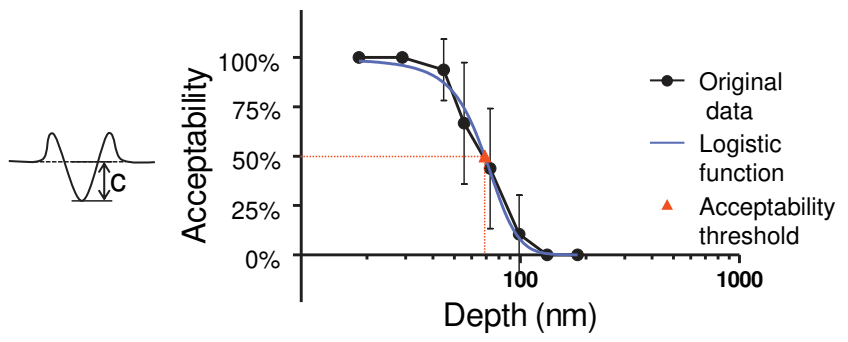

(c)

Fig. 5. Acceptability of the scratches as a function of the parameters of the scratch. (a) Width between two peaks, (b) width at the surface and (c) depth.

parameter $b$ gives a visibility threshold of $0.72 \mu \mathrm{m}$. The acceptability threshold corresponding to a $0.88 \mu \mathrm{m}$ wide scratch is the results of a whole group subjective perception. Referring to the results shown in Fig. 2, standard visible and acceptable scratches can be found by interpolation. The just noticeable one corresponds to a normal force $F n$ of $1600 \mu \mathrm{N}$ and the just acceptable one to a normal force of $2300 \mu \mathrm{N}$. This data can be used afterwards to create new standard samples which can be employed in a polishing company.

\section{Conclusion}

A procedure for manufacturing standard scratches has been developed with a nanoindenter and a Berkovich tip. The control of the normal force guarantees a uniform scratch throughout the length. The range of the scratch set extends from the invisible ( $400 \mathrm{~nm}$ wide) to the very visible ( $2000 \mathrm{~nm}$ wide). An analysis of the vision and judgment of experts in jewellery quality has been proposed. The samples created highlight the differences in judgments according to 12 various subjects. Subjects with a different experience and different behaviors do not have the same vision and the same decisions. However, it is possible to establish thresholds of visibility and acceptability of scratches by referring to the whole group. The threshold of visibility is approaching the one from literature for a scratch width of $700 \mathrm{~nm}$. The threshold of acceptability is itself fixed to $880 \mathrm{~nm}$ wide. The fact that each individual have subjective decision criterion causes over-quality problems. This task is especially difficult in transition zones described previously. The use of standard samples would help to select the right decision in cases where any doubt exists. These samples can be used to normalize accurately the will of any other company through further training.

\section{References}

[1] Debrosse T, Pillet M, Maire J, Baudet N. Sensory perception of surfaces quality, industrial practices and prospects. In: International conference on Kanse engineering and emotion research. 2010.

[2] Fechner G. Elements of psychophysics. Leipzig: Holt, Rinehart and Winston 1966.

[3] Guerra A. Métrologie sensorielle dans le cadre du contrôle qualité visuel. Ph.D. thesis. Université de Savoie, SYMME Laboratory; 2009.

[4] Guerra A, Pillet M, Maire J. Control of variability for man measurement. In: 12th IMEKO TC1 TC7 joint symposium on man science measurement. 2008.

[5] Hecht S, Mintz E. The visibility of single lines at various illuminations and the retinal basis of visual resolution. Journal of General Physiology 1939;22: 593-612.

[6] Kermouche G, Loubet J, Bergheau J. Extraction of stress-strain curves of elastic-viscoplastic solids using conical, pyramidal indentation testing with application to polymers. Mechanics of Materials 2008;40(4-5):271-83.

[7] Laughlin S. The role of sensory adaptation in the retina. Journal of Experimental Biology 1989;146:39-62.

[8] Lefebvre A, Bassereau J, Harris N, Duchamp R, Pensé A. Caractérisation d'une surface par évaluation sensorielle: contribution à l'optimisation d'un procédé de dépolissage de bouteilles en verre. In: Conception et production intégrées; 2005.

[9] Takeuchi T, Puntous T, Tuladhar A, Yoshimoto S, Shirama A. Estimation of mental effort in learning visual search by measuring pupil response. PLoS ONE 2011;6(7):e21973. 